\title{
PROBLEM FRAMING IN UNIVERSITY-INDUSTRY COLLABORATIONS: THE CASE OF KNORR
}

\author{
Linda Nhu LAURSEN ${ }^{1}$ and Louise Møller HAASE ${ }^{2}$ \\ ${ }^{1}$ Assistant Professor, Department of Architecture, Design and Media Technology \\ ${ }^{2}$ Associate Professor, Department of Architecture, Design and Media Technology
}

\begin{abstract}
Universities increasingly welcome student-industry collaborations. The rationale is, while the collaborating company are introduced to new valuable knowledge, students gain experience with real life challenges. However, experience shows it may be challenging for a company to get the desired outcome from university collaborations. Company's report that the students' work outcome is disappointing; it does not add any new knowledge. Oppositely many university teachers reject industry projects as they find that the learning may be compromised, in favour for industry demands.

In this study we examine how to frame problems for successful industry-university collaborations. We explore two key dimensions in respect to the problem framing. First of all, we explore the value of students tapping into knowledge and experience domains, where their expertise is higher than the industry partners. And we explore the influence problem framing openness has on the outcome of student work, as well as the satisfaction on both sides.

In this study we have set up a university-industry collaboration, where we connect the problem framing directly with one of the students' experience domains, to explore whether, and if, this may produce more valuable output. Secondly, we have set up two quasi-experiments, where we vary the openness of the problem frame. The study indicates that connecting the problem framing to an experience domain, where the students have more expertise than the industry partner, can be highly valuable for the result. Moreover, the study highlights the importance identifying the company's implicit assumptions and challenges with respect to the problem frame.
\end{abstract}

\section{Keywords: Task, industry-university collaboration, design educations}

\section{INTRODUCTION}

University-industry collaboration is increasingly perceived as attractive. Universities typically welcome industry challenges as students are faced with the complexity of reality. In return, the collaborating company receives free resources, often on a task, where the company needs a new perspective or has limited resources available. It all sounds ideal. Like a win-win situation, companies should be queuing up to. However, experience shows it may be more challenging for companies to get a useful outcome from student work. In some circumstances, companies report that the output of the students' work is disappointing; it does not add anything new. Oppositely with other tasks, the lecturer complains students learning is compromised, while the company may have gained a relevant output. The critical challenge is integrating students' learnings and industry relevant output.

In this study, we examine how to define projects for university-industry collaboration, which integrates both learning demands as well as industry relevant output. Past research indicates a central means for directing the problem-solving process and the final outcome is the way a problem is framed (Vaccaro et al., 2011; Simon, 1973). The way problems are framed shapes the process as it directs problem-solvers to utilise and deploy specific skills, knowledge and capabilities (Von Hippel, 1990), hence it influences the learning process. Furthermore, the level on which a problem is specified directs the outcome, as it either opens up exploring a diversity of solutions or pre-sets a focused delimitation. In this study we research how different problem framings in industry-university collaboration may work to enhance students learning as well as unlocking knowledge that is valuable for the company.

Framing problems to students in a way that enables the desired process and knowledge output is not straight forward. At universities the lecturer or professors typically hold the responsibility for, and are 
trained, in crafting tasks that facilitates student learning. This is, moreover, often formalised in documents, such as learning goals, study plans etc. Whereas, framing a problem, in a way that as well enables students to additionally contribute with the desired knowledge for a company, is a less organised area. Students are in a learning situation with everything that entails. They may be characterised as novices, that have limited experience, compared to the trained finished educated professionals within the company. Thus, for the company to gain new insight from students, it is central the problem is framed to focus on aspects, where the students hold or may provide knowledge, that is new and unexpected for the company.

Previous literature has discussed problem framing for new innovations as a trade-off between: On one hand, identifying the desired output, where the task is too narrow and bound the problem frame, in order to secure focused interaction, contributing dialogue and relevant knowledge exchange (Slowinski et al., 2009). On the other hand, setting too narrow and specialised boundaries might set cognitive limits that in return result in a disregard of valuable high level and out-of-category knowledge contributions, that the task setter was unaware of (Brusoni, 2005). In the present study, we want to explore this further.

To examine problem framing in an industry-university setting, the study is divided into three steps. First, we review the literature on problem framing and relate this to problem framing in a university-industry setting. Second, we use this review to build a theoretic model of problem framing, which is useful in respect to setting the boundaries for the students' didactic experiences as well as shaping the potential output. More specifically, the model reveals how to organise and filter incoming project information through problem frames, and define what issues are relevant. Third, we test the model in a universityindustry collaboration, where we setup two quasi-experiments between the same case companies and two different university student classes.

\section{PROBLEM FRAMING}

Problem framing may be defined as the articulation of a task. It refers to how we specifically "name things to which we will attend and frame the context in which we will attend to them" (Schön, 1983, p.40). The problem frame sets the arena, hence defines the space and the overall conditions in which the problem may be understood and may be solved (Newell, 1979, p. 5). The research on how to articulate a problem has been widely discussed in different streams of literature, under labels such as problem space (Newell, 1979), problem structure (Simon, 1973), task structure (Von Hippel, 1990; Hirokowa, 1990) as well as problem framing (Buchanan, 1992). Common to these studies are that they recognise and examine the significance of how problems may be framed. The central idea in the concept of problem framing is the articulation of the task is an important determinate of both the following problem-solving process and the final outcome.

Past research shows the articulation of a prevailing problem affects the process of solving the problem (Von Hippel, 1990; Newell, 1979). When a problem is specified, the incoming information is related and filtered through that frame, in a way that serves as a device for sense making (Weick 2001). In the problem-solving process, participants use the problem framing for orientation and evaluation of the following process of knowledge gathering and development. The problem frame determines what is being noticed, dealt with and acted upon in subsequent problem solving (Shazer, 1988). In fact, Schön and Rein (1994) describes how problem frames represent underlying structures of belief, perception and appreciation. By inducing implicit assumptions about relevant issues, priorities and evaluation criteria, it sets the rules of the game, and influences the knowledge utilised in the problem-solving process (Abdel-Halim, 1983). Problem framing is as such a conceptual positioning that shapes the situation but also the following solution (Buchanan, 1992).

Research indicates the way you articulate a problem influences the final outcome. A key challenge when framing a problem for a design, innovation and new product development outcome, is framing a problem so that it both focuses on problem solving and opens up towards new unexpected solutions. On the one hand a broad and abstract definition of a problem may be more open towards novel knowledge inputs and new opportunities. An open problem leaves much of the interpretive work to the problem-solver. This may bring about a more diverse search for ideas among problem solvers, that in return brings notions to the table, the problem-setters had not thought of (Jeppesen \& Lakhami, 2010). Nevertheless, the problem-solving of an open and abstract problem may be experienced as unfocused, since the problem needs to be continually developed and further defined, through an iterative process of discussion and elaboration (Burns \& Stalker, 1961). On the other hand, when a problem is narrowly specified, presenting substantial detail, it brings out the advantage of driving focused effective 
knowledge exchange. Thus, the level and the way problems are specified is an important design parameter for influencing the outcome. Framing a problem for an innovative solution is a balancing act between "precisely problem-solving and the generation of new information" (Von Hippel, 1990, p 408). Building on past literature, we argue the openness of a problem framing may be specified by respectively by 1) the clarity of goal, hence the end state that should be achieved and 2) the clarity of the path toward the goal, hence the means to achieve the goal (Hirokowa, 1990; Robillard, 1999; Laursen and Andersen, 2015).

\subsection{Problem framing for students}

Framing problems to students, in ways that enable the desired output for industry, is not straight forward. Students are inexperienced and may be regarded as novices in many knowledge areas; we argue this is an important consideration when framing the problem. Literature points at the expertise and confidence level of the problem solvers may be an important factor in setting the problem frame. Rittel and Weber (1973) elaborates: "The level at which a problem is settled depends upon the self-confidence of the analyst and cannot be decided on logical grounds... Of course, the higher the level of a problem's formulation, the broader and more general it becomes; and the more difficult it becomes to do something about it. On the other hand, one should not try to cure symptoms: and therefore, one should try to settle the problem on as high a level as possible." (Rittle and Webber, 1973:165). We argue confidence levels vary with the experience the problem-solver has gained in different areas. Hence an experienced designer, may have a high confidence level in design and may as such be posed a complex design problem, that they themselves can break down and tackle, drawing on past experiences. Whereas their experience, in finance problems, is on a much lower level. Thus, adding to previous studies on problem framing, and in particular when posing tasks to students, we argue it is important to take the experience domain of the problem-solvers into account.

\subsection{The problem-framing model}

Based on the theoretical insight, we have created a problem-framing model for university-industry collaboration that shows some of the important aspects to consider in respect to framing the problem for the students. First of all, the proposition or confidence of the student in respect to the specific assignment - is important to consider. We suggest that if problems are framed so they tap into domains, where the students are more experienced than their industry partner and hence more confident, the likelihood of students developing a valuable outcome is higher.

Secondly, the problem framing openness - understood as how clear both the goal and the path towards the goal is - is likewise important to consider. We assume that finding the right level of openness in respect to the problem framing will have a significant influence on the success of the project (measured in students perceived learning and the company's satisfaction with the project).

\section{METHODOLOGY}

In order to explore how problems may be framed to provide a higher likelihood for a valuable outcome for both students and company's in university-industry collaboration, we set up a study based on the problem-framing model.

First of all, we set up a university-industry collaboration that included one central domain, where the students' knowledge and experience was higher than the industry partners. The intention of this was to provide the student with more confidence going into the assignment and assuring that the industry partners would gain some new and unexpected knowledge from the project. The assignment had a specific focus on the young Nordic food market. Hence, the students themselves would be the main target audience of the products they developed. This also meant that the students' insights into their own habits and preferences could be seen as an experience domain where they had more in-depth knowledge and experience than the industry partner, Unilever. Secondly, we set up two rounds of quasi-experiments where the problem framing was varied, and the outcome is evaluated both in respect to students' perceived learning and the company's satisfaction with the project. Quasi-experiments are non-intrusive field intervention, where something is manipulated in order to study an assumed effect. As such it is a kind of field stimulation, which makes it possible to zoom in and examine a specific aspect of attention in order to better understand it (Shadish, Cook, \& Campbell, 2002). In the collaboration with Unilever, we set up two successive experiments, varying the openness of the problem framing in relation to the students' knowledge domain. 


\subsection{Experiment setup}

The first experiment was a three-week workshop with 30 experience design, interaction design and industrial design students on the $5^{\text {th }}$ semester (in the following referred to as Workshop A). The students worked in groups of approximately four, in a workshop cross-functional format, where they in the curriculum where to learn different approaches for user research. For the first experiment, the problem was framed so the goal and the path are kept open, to allow for exploration and opportunities to identify novel output for the company. More specifically the problem framing for experiment A is as following: Project brief: Re-imagining the experience and concept of fluid meals*

Definitions *Re-imagining: Visualising beyond today. *Experience: The involvement and interaction from first till last encounter. *Concept: The key idea of a solution, what it is and how it works. *Fluid meal: Soups, stews, purees etc.

Task: Unilever and its food brands are trying to reach the young Nordic market. Please help us create an aspirational fluid meal concept, that you yourself would consume once a week for the next year!

Initially the company wanted the students brief for developing a soup, however in collaboration with the researcher, who wanted to push for new unexpected knowledge input, the problem was reframed and opened up to 'fluid meals' not specifying a specific format. Instead the higher-level goal was emphasised, namely something that targets millennials (the students). Moreover, the goal of capturing the millennials was formulated very concretely in the problem framing as 'Please help us create an aspirational fluid meal concept, that you yourself would consume once a week for the next year' the language was kept in everyday, to directed and to tap into student's own experience of preferences.

The second experiment was a one-week workshop setup with 24 industrial design students on the $7^{\text {th }}$ semester (Workshop B). The students worked in groups of approximately three. In the second experiment, the task is narrowed significantly:

Project brief: From 'mash/oats product concept' for Knorr that is desirable, feasible and viable*

Definitions: *Mash: vegetable pureeloats: oatmeal. *Desirable: What you want, 'you would want to eat once a week'. *Feasible: What the company can build.*Viable: What the company can profitably deliver.

Task: Unilever is trying to reach the young Nordic market. Please help us take a mash or an oats concept and mature it into a holistic product, that feasible and viable for the business; and that is desirable hence you would purchase it once a week for the next year!

We settled the product type and the packaging format for you, please help us settle the concept.

Hence in the task the goal in terms of content type and the packaging format was fully specified. The idea was limiting and focusing the students' problem-solving, so they were forced to work within a knowledge domain, in which they had extensive experience. Namely, their own everyday eating preferences.

In the experiments, we acted as second lecturer in the sense we did not have full responsibility over the course or the project, instead we were the connecting actor between the company (that had a challenge) and the lead lecturer for the course (which has the responsibility for the setting the circumstances for students learning). We choose this setup in both experiments, as we wanted ensure students learning, weren't compromised; moreover, we strived to take an observational role.

\section{EXPERIMENT RESULTS}

The two experiment problem framings lead to significantly varied results. Workshop A with the open problem framing lead to six concepts, where two of them were regarded as interesting, hence selected by the industry partner for further exploration. The work lead to a very diverse set of concepts, including healthy morning pancakes, lunchbox plus with fresh organic vegetables, oats with healthy toppings, customised modular snack pots, a mix and match modular mash concepts that suit different diets, customised spice mix and customised freeze-dried food concept. However, beyond the actual outcome, in terms of the two preliminary concepts, the company gains two significant implicit learnings from what the students did not propose. First, it was a quite valuable insight that none of the students in fact had developed a soup, which the company beforehand assumed to be key in unlocking the Nordic millennial market. Moreover, the variety and diversity of concept had a common feature. None of them actually proposed a dinner concept, which had previously been Knorr's main market. Instead the students proposed in-between snacking meals. 
At a more overall level, Workshop A provided both students with a highly valued learning process as well as the collaborating company with a valuable result.

Workshop B with the narrow problem framing used the two selected product formats from experiment A to pose a very narrow task where the students were asked how such product format could make sense and be valuable for them. The task was to further develop and mature the ideas. From the experiments nine main concepts were developed. The nine concepts were more diverse than initially expected, the students had reframed the task suggesting soups, different types of mashes, organic oats, vegan balls and energy breakfast oats. From these nine concepts three were selected to be furthered within the company, and two months after several variations prototypes and further development were made, drawing inspiration from these three concepts. Like in the previous workshop, workshop B provided both students with a highly valued learning process as well as the collaborating company with a valuable result.

Together the two workshops present two highly different problem framing situations, ranging from a very abstract high-level to a concrete decomposed problem, however they both tap into a domain of experience, where the students have more knowledge than the company. Both workshop tasks draw on the students' tacit knowledge of their everyday context, their habits, preferences and aspirations. Thus, beyond the actual outcome the company in both cases report on deep insight, on customer tacit inexplicit consumer preferences that are hard to communicate, which the students through their proposal model and capture. Aspects which they might not themselves be aware of, as millennials say organic, vegan, healthy, but drink energy drink for breakfast; hence they developed the concept the 'red bull' of breakfast.

\section{DISCUSSIONS AND IMPLICATIONS}

In this paper, we have explored the university-industry collaboration, and more specifically the task of creating a problem framing that will provide valuable results and outcomes for both the students as well as the industry partner.

The study reveals two important dimensions to consider for fully deploying the students' potential in a university-industry collaboration. First, the considerations of students' novice vs expertise knowledge domains in relation to the company. As the students in many regards have less experience, than their corporate counterparts, the key is to identify aspects or areas, which either have been less explored by their corporate collaboration partner or area where the students, despite their inexperience are more knowledgeable. Identifying the 'sweet spots' where students hold incomparable ensures the exchange of highly valuable knowledge. For example, when the design students' use their design skills to develop proposals, they beyond the actual proposal, reveal implicit and tacit knowledge of own habits, eating preferences and perceptions of the Knorr brand. These serve to be just as valuable for the company, as the 'actual' proposals. They give an indication of direction, which is hard to

Second, identifying the company's' implicit assumptions in framing the problem and challenges in order to identify the right abstraction level. For example, when the company's request a new soup, maybe they in reality want any product that is an in-between/light meal and opening the problem to embrace such framing may allow the students to be helpful in identifying this. This moreover shows that company's output may not only be in terms of what is directly developed, which is the case of workshop B, where they use the products for maturation, but also the market insights from what the students' proposals did not concern or was centred around.

\section{REFERENCES}

[1] Vaccaro A., Brusoni S. and Veloso F.M. Virtual design, problem framing, and innovation: An empirical study in the automotive industry. Journal of Management Studies, 2011, 48(1), 99-122.

[2] Simon H.A. The structure of ill-structured problems. Artificial Intelligence, 1973, 4, 181-201.

[3] Von Hippel E. Task partitioning: An innovation process variable. Research policy, 1990, 19(5), 407-418.

[4] Slowinski G., Hummel E., Gupta A. and Gilmont E.R. Effective practices for sourcing innovation. Research-Technology Management, 2009, 52(1), 27-34.

[5] Brusoni S. The limits to specialisation: problem solving and coordination in 'modular networks'. Organisation Studies, 2005, 26(12), 1885-1907.

[6] Schön D.A. The Reflective Practitioner: How Professionals Think in Action. New York: Basic Books. 1983. 
[7] Newell A. Reasoning, problem solving and decision processes: The problem space as a fundamental category. In R.S. Nickerson (Ed.), Attention and Performance. Hillsdale, NJ: Lawrence Erlbaum. 1980.

[8] Hirokawa R.Y. The Role of Communication in Group Decision-Making Efficacy A TaskContingency Perspective. Small group research. 1990. 21(2), 190-204.

[9] Buchanan R. Wicked Problems in Design Thinking, Design Issues, 1992. Vol. 8, No. 2, p. 5-21.

[10] Weick K.E. Sensemaking in organizations (Vol. 3). Sage. 1995.

[11] Shazer S. Clues, Investigating solution in Brief Therapy Norton \& Company Inc.: New York. 1988

[12] Schön D.A. and Rein M. Frame Reflections, New York: Basic Books. 1994.

[13] Abdel-Halim A.A. Effects of task and personality characteristics on subordinate responses to participative decision making. Academy of Management Journal. 1983. 26(3), 477-484.

[14] Jeppesen L.B. and Lakhani K.R. Marginality and problem-solving effectiveness in broadcast search. Organisation science. 2010. 21(5), 1016-1033.

[15] Burns T.E. and Stalker G.M. The management of innovation. University of Illinois at UrbanaChampaign's Academy for Entrepreneurial Leadership Historical Research Reference in Entrepreneurship. 1961.

[16] Rittel H. and Webber M. Dilemmas in a General Theory of Planning. Policy Sciences. 1973. 5, 155-69.

[17] Robillard P.N. The role of knowledge in software development. Communications of the ACM. 1999. 42(1), 87-92.

[18] Laursen L.N. and Andersen P.H. Supplier involvement in NPD: a quasi-experiment at Unilever. Industrial Marketing Management, 2016, 58: 162-171.

[19] Shadish W.R., Cook T.D. and Campbell D.T. Experimental and quasi-experimental designs for generalised causal inference. Boston: Houghton Mifflin. 2002. 